\title{
Sobre libertad e igualdad religiosas
}

\author{
Mercedes de la Garza Camino
}

$\mathrm{H}$

oy día, la vida en sociedad no puede existir ya sin el reconocimiento de los derechos humanos en materia religiosa. En su artículo 18, la Declaración Universal de los Derechos Humanos, aprobada por la ONU el 10 de diciembre de 1948, consagra la libertad religiosa: "Toda persona tiene derecho a la libertad de pensamiento, de conciencia y de religión, así como la libertad de manifestar su religión o su creencia, individual y colectivamente, tanto en público como en privado, por la enseñanza, la práctica, el culto y la observancia”.

En épocas anteriores a los derechos humanos, la libertad religiosa no se consideraba una virtud, sino una flaqueza y hasta una cobardía. Tolerancia era complicidad. De ahí el gran mérito de John Locke, que publica en 1689 su Epístola de tolerancia, donde afirma:

Vosotros los que practicáis el culto católico; y vosotros también, los de Ginebra; y vosotros, remostrantes, contrarremostrantes, anabaptistas, arminianos, socinianos, sabed que nunca dominareis un alma por la fuerza; no teneis ni derecho ni poder para ello. Toleraos; y unidos en la voluntad de hacer el bien, amaos los unos a los otros. ${ }^{1}$

A partir de la Declaración Universal de los Derechos Humanos, surgen múltiples declaraciones internacionales más y diferentes tratados que han sido esenciales logros culturales de nuestro tiempo; puedo mencionar también la "Declaración sobre la eliminación de todas las formas de intolerancia y discriminación fundadas en la religión o las convicciones", que fue aprobada por la

${ }^{1}$ Raúl González Schmal, "Libertad y tolerancia religiosa en México. El caso de la comunidad judía”, en Memoria del Seminario Internacional sobre Tolerancia. México, Comisión Nacional de los Derechos Humanos, 2001, p. 124. 
Asamblea General de las Naciones Unidas el 25 de noviembre de 1982. Esta declaración se apoya en uno de los principios básicos que han de regir la vida del hombre: el respeto a la dignidad e igualdad consustanciales a todos los seres humanos. ${ }^{2}$

De este modo, hoy debiera ser evidente para todos que cualquier persona tiene derecho a la libertad de pensamiento, de conciencia y de religión. En medio de los grandes males del siglo Xx, la cultura occidental ha conseguido establecer estos principios que ahora nos parecen elementales, ponerlos por escrito y obligar a su cumplimiento, a pesar del triunfo secular de la injusticia, la violencia, el atropello de los fuertes contra los débiles y de las mayorías contra las minorías, el narcisismo abyecto de creer que mis costumbres son las debidas, mi "raza" es la buena, lo bello es lo que yo construyo, mi Dios es el único y mi religión la verdadera.

Raúl González Schmal asienta:

El siglo Xx, que apenas acabamos de remontar, es el siglo más violento de la historia, el de los genocidas que hacen de la intolerancia la mayor expresión de la patología criminal, pero también es el siglo de las libertades y de las sociedades abiertas. El sentimiento de la absolutez de la libertad es el sentimiento fundamental del espíritu del siglo Xx. Se inicia un proceso que ya es irreversible, de internacionalización de las libertades y los derechos humanos. ${ }^{3}$

Efectivamente, a pesar de los horrores del siglo xx y de que vivimos actualmente una aguda crisis de deshumanización, hemos logrado mucho en el terreno de la libertad y la igualdad, nos hemos hecho conscientes de que precisamente lo más humano del hombre es trascender esa ley animal del más fuerte y lograr el respeto al libre albedrío y a la dignidad; y ello es tarea justamente de la conciencia y la libertad que nos distinguen del animal, aunque biológicamente sólo nos diferenciamos de él en un $0.1 \%$ de nuestro genoma, como ha mostrado la actual ciencia genómica. Asimismo, esta nueva ciencia ha descubierto que las diferencias entre los distintos hombres sólo llegan a un $0.08 \%$. Desde esta perspectiva, el concepto de "raza" ha quedado limitado a diferencias meramente externas, como el color de la piel o los rasgos faciales, pero ¿ese hallazgo científico ha eliminado la discriminación y el racismo? y la aceptación universal de los derechos humanos, entre los que está la libertad de creencias, ¿ha eliminado la violación de esos derechos? ¿Ha acabado con el

\footnotetext{
${ }^{2}$ R. González Schmal, "Presentación”, en op. cit., p. 9.

${ }^{3}$ Ibid., p. 125.
} 
fanatismo y con los sangrientos enfrentamientos religiosos en nuestro país y en otros muchos?

Infortunadamente no es así, el fanatismo y la intolerancia, que llegaron a su clímax en el siglo $\mathrm{xx}$, persisten hasta nuestros días, como son prueba clara de ello, entre muchos otros hechos, los conflictos religiosos al interior de las propias comunidades (Yugoeslavia, Irlanda, México) y la guerra de Irak, que de la manera más burda se ha justificado en la convicción de que "yo soy el bien y los otros son el mal", siguiendo los principios del fundamentalismo estadounidense, manifiesto ahora en los new born, o "cristianos renacidos". 4

Y es común también hoy el grave problema de ciertas creencias y cultos que atentan claramente contra las leyes y los derechos humanos en sus propios ritos, como los casos de los grupos narcosatánicos, que sacrifican niños, y aquellos que inducen a los adeptos al suicidio, prácticas que resultan hoy ética, jurídica y humanamente inaceptables, así como son intolerables el racismo, el terrorismo y la tortura. Parece evidente para todos que no se pueden ni deben aceptar situaciones indignas del hombre.

Pero también son rechazables éticamente los grupos "religiosos", que embaucan a personas necesitadas de auxilio espiritual y sólo buscan dinero y poder, como la "Asociación del espíritu santo para la unificación del cristianismo" fundada por el reverendo Sun Myung Moon en Corea del Sur, que tiene 200000 adeptos en todo el mundo. ${ }^{5}$ Dentro de la muy compleja problemática de la libertad y la igualdad religiosas, me limitaré a destacar en seguida dos aspectos centrales: 1. La consideración de la religión como un hecho histórico, desde la perspectiva de la ciencia de las religiones, y 2. El conflicto

${ }^{4}$ En 1979, el predicador televisivo Jerry Falwell funda el movimiento de la "Mayoría Moral" en Estados Unidos, con la pretensión de movilizar y organizar políticamente a los aproximadamente sesenta millones de estadounidenses que se denominaban a sí mismos "cristianos renacidos". Esta movilización apoyó la victoria electoral de Ronald Reagan y George Bush se considera a sí mismo "renacido". Los fundamentos de este movimiento son: contra concepciones seculares y ateas de la vida (feminismo, aborto, comunismo, liberalidad moral...), defensa de una imagen cerrada del mundo, confrontación de los poderes de la luz contra Satán y los poderes de las tinieblas; revitalización de las raíces religiosas de la propia nación, identificadas como puras y dadas por Dios, mientras que los poderes del mal están fuera de la nación y de la propia religión; conciencia de una misión universal de salvación del mundo (José A. Zamora, "La invasión de Irak y el fundamentalismo religioso estadounidense", Seminario Internacional: "La filosofía después del holocausto", Instituto de Filosofía del Consejo Superior de Investigaciones Científicas. Madrid, <www.ifs.csic.es $>$ ).

5 Moon es un megalómano que radica en Uruguay, tiene vínculos con nazis, fascistas y los escuadrones de la muerte de Suramérica; tiene casas de lujo en distintos países; se presenta como encarnación del Mesías y pretende crear el paraíso terrenal en Brasil. 
entre la universalidad de los derechos humanos y la particularidad de los derechos culturales en el terreno religioso.

\section{La religión como hecho histórico}

¿En qué se basan intrínsecamente la libertad y la igualdad religiosas, ya que los fundamentalistas y muchos otros siguen hoy proclamando que la suya es una verdad revelada por la misma divinidad y, por tanto, es legítimo imponerla y destruir a las otras?

Dejando a un lado la muy frecuente utilización de la religión como instrumento político, y toda la problemática en torno a ello, aquí queremos destacar que también es un logro de nuestro tiempo el abordaje científico de las religiones, consideradas como objeto de estudio, como hechos que es posible analizar en el contexto de las sociedades que las han creado. Hoy se reconoce que la religión es un fenómeno histórico, como todas las demás creaciones del espíritu humano, es decir, que cada religión surge en un tiempo y un espacio determinados. Los hechos religiosos son productos culturales del hombre, y por ello, no pueden comprenderse fuera de su contexto temporal, cultural y social.

Por hecho o fenómeno religioso la ciencia de las religiones entiende aquello que el hombre expresa de su relación con una realidad que considera trascendente y superior: lo sagrado. El vínculo con lo que se considera sagrado es una experiencia inefable que puede ser racional o emocional y que no se conoce sino a través de las expresiones del hombre religioso; por tanto, estas expresiones siempre se dan en un contexto histórico. A esto se debe que Michel Meslin las llame "lo sagrado vivido". 6

Por consiguiente, los fenómenos religiosos no son lo sagrado, cuya existencia es únicamente objeto de fe, sino imágenes, símbolos, ritos, es decir, lenguajes humanos acerca de la experiencia de lo sagrado.

Y además, el fenómeno religioso ha de estudiarse en un marco de referencia complejo que tome en cuenta que es también un hecho psicológico, sociológico, lingüístico y antropológico, entre otros. Considerar sólo uno de sus aspectos desvirtúa el fenómeno religioso en lo que tiene de original, es un reduccionismo que impide comprenderlo cabalmente, porque el hecho religioso tiene una forma de ser propia: es, precisamente, un hecho religioso, un fenómeno sui generis, irreductible y original, y además es muy complejo. En el estudio de su objeto, la ciencia de las religiones debe entonces

${ }^{6}$ Michel Meslin, "Introducción", en Aproximación a una ciencia de las religiones. Madrid, Cristiandad, 1978, p. 134. 
utilizar los resultados de otras ciencias e integrarlos para aplicarse a la búsqueda de los significados; esta disciplina pertenece al campo de las ciencias humanas, pero no se reduce a ninguna de ellas, pues tiene su propio objeto y sus propias funciones.

La ciencia de las religiones se presenta, entonces, como una disciplina muy diferente de la teología, que ha imperado durante siglos en la cultura occidental; mientras que la teología se ocupa de Dios y es una disciplina normativa, cuyo fin es asentar qué se debe creer y por qué se debe creer eso, la ciencia de las religiones se ocupa del hombre religioso en su situación histórica, por ello, es una ciencia humanística.

Y desde esta perspectiva, es claro que no hay una religión verdadera y otras falsas. Las religiones "reveladas", es decir, las que sostienen que Dios ha revelado a un hombre o a un pueblo su existencia y las normas que debe cumplir, y por tanto ese dios y esas normas son la verdad absoluta, sólo lo son para los creyentes en esa religión, no una verdad objetiva.

Obviamente, estas consideraciones son esenciales para defender y apoyar la libertad y la igualdad religiosas.

\section{Los derechos humanos y los derechos culturales}

Un problema central de la libertad religiosa es la disyuntiva entre la universalidad de los derechos humanos, que son su fundamento, y las particularidades de los diferentes grupos sociales, manifiestas en los llamados derechos culturales, pues cuando hablamos de derechos humanos, ¿estamos hablando todos de lo mismo? ${ }^{7}$

Si bien cada pueblo tiene sus propios valores y costumbres morales, sus propias creencias, ¿hay valores que se puedan considerar universales, de tal modo que, por ejemplo, la tortura, el sometimiento, la violencia, la miseria, sean universalmente condenados por los seres humanos? ¿Hay derechos mínimos comunes a todas las culturas que puedan sustentar las diferencias?

Entre los atentados a la libertad de creencias y costumbres, que han sido abominables a lo largo de la historia, destacaré las crueldades y asesinatos en el seno de las comunidades indígenas mayas, tanto en Guatemala como en México, apelando unos a la libertad individual de convertirse a cualquier religión, y los otros a la violación de la identidad étnica que parece conllevar tal libertad individual.

${ }^{7}$ Rafael del Águila, "Los derechos humanos y algunos de sus problemas en el mundo de hoy", en Pedro Pitarch y Julián López García, Los derechos humanos en tierras mayas. Política, representaciones y moralidad. Madrid, Sociedad Española de Estudios Mayas, 2001, p. 19. 
Desde los años sesentas, alrededor de 30000 indígenas mayas han sido exiliados violentamente de sus pueblos de origen, la mayoría de ellos, de San Juan Chamula, porque se han convertido a diversas religiones evangélicas, como las protestantes (luteranos, calvinistas, metodistas y presbiterianos), los testigos de Jehová, los pentecostales, los mormones, los adventistas del séptimo día, el catolicismo diocesano, etcétera. Estos exiliados han fundado nuevos asentamientos como Palestina, Nueva Esperanza y Paraíso, que son todo lo contrario al significado de sus nombres. Los causantes del exilio son los líderes indígenas locales que siguen la llamada "costumbre", nombre que dan a la religiosidad tradicional, que incluye elementos prehispánicos, aunados al culto a los santos católicos y cuyos ritos están a cargo de chamanes, curanderos y adivinos. Ellos consideran que las otras religiones, al amenazar "la costumbre" amenazan, en consecuencia, la solidaridad comunitaria y la identidad. ${ }^{8}$ Aquí, el conflicto entre "tradición indígena" y derechos individuales es central. La expulsión viola, sin duda, los derechos humanos protegidos por la Constitución mexicana y la Declaración Universal de los Derechos Humanos, pero los líderes de Chamula asientan que su identidad y cohesión como grupo se finca en su religión tradicional, a la que añaden su afiliación al PRI; por tanto, los que se convierten a los cultos venidos de fuera, junto con los que apoyan a partidos políticos distintos, deben ser expulsados.

Por su parte, los nuevos movimientos religiosos acusan a los tradicionalistas de ser paganos y, según Mario Ruz, "se han revelado bastante más capaces que la Iglesia católica para dar respuesta a las nuevas demandas y necesidades (individuales y sociales) de los sectores más marginados [...] en tanto que han permitido romper los antiguos monopolios económicos y religiosopolíticos, amén de mostrarse a menudo más creativos en cuanto a métodos proselitistas se trata". ${ }^{9}$ Estos grupos tienen sus servicios religiosos en los idiomas indígenas y emplean Biblias traducidas a estas lenguas, en tanto que los sacerdotes católicos, que apenas participan en los ritos de "la costumbre", no siempre hablan alguna lengua indígena y practican el celibato, que para los indígenas es anormal.

La expulsión ha sido considerada como una violación de los derechos individuales para proteger los colectivos, pero ésta es una forma simplista de

${ }^{8}$ Christine Kovic, "Para tener vida en abundancia: visiones de los derechos humanos en una comunidad católica indígena”, en P. Pitarch y J. López García, op. cit., pp. 275-276.

${ }^{9}$ Mario H. Ruz, "De iglesias, conversos y religiosidades mayas", en Protestantismo en el mundo maya contemporáneo. México, UNAM, Instituto de Investigaciones Filológicas/UAM, División de Ciencias Sociales y Humanidades, 2005 (Cuadernos del Centro de Estudios Mayas), p. 8. 
abordar el problema. No hay que olvidar que el fundamentalismo surgió precisamente entre los protestantes estadounidenses y que la identidad de las comunidades indígenas se caracteriza por una conciencia de grupo, es una identidad grupal; que están regidos por sus propias costumbres o tradiciones o por una legislación especial y tienen derecho a ejercer la autodeterminación y a conservar todas sus instituciones sociales, económicas, culturales y políticas. Pero ¿ello significa que si algún individuo lo desea, ha de negársele su libertad de cambiar de religión? Idealmente, la identidad grupal no debiera impedir la libertad individual, pues se trataría de otra forma de imposición y de dogmatismo, pero si en verdad la libertad individual de abandonar la tradición socava la identidad comunitaria, ello parece inadmisible.

Varios pensadores, entre los que está Carlos Monsiváis, consideran como una falacia afirmar que la intrusión del protestantismo en el mundo indígena atenta contra la identidad cultural ${ }^{10}$ y nosotros nos preguntamos ¿en verdad pierden la identidad aquellos que se convierten a otros credos? ¿Se debe prohibir la libertad de cultos en aras de preservar las "culturas ancestrales"? ¿No son ellas actualmente un crisol, vivo y en movimiento, donde se han fundido y se funden múltiples creencias religiosas? La identidad ¿es un absoluto eterno e inmóvil? Dice el politólogo español Rafael del Águila:

[...] ya no existen sociedades tradicionales "intactas" (si es que alguna vez las hubo) y, como demuestra el fundamentalismo islámico, todo intento de mantenerlas así exige una fuerte presión autoritaria sobre poblaciones cada vez más híbridas en sus valores y creencias. ${ }^{11}$

En lugar de derivarse de una cultura primordial o a priori -sostienen Sieder y Witchell- las identidades son creadas y recreadas históricamente a través de interacciones mutuamente constituidas entre distintos actores, contextos e ideas. ${ }^{12}$

Por ello -como afirma Stavenhagen - una cultura tiene especial vitalidad si es capaz de preservar su identidad al tiempo que incorpora el cambio. ${ }^{13}$

Y Luis Villoro afirma:

${ }^{10}$ Carlos Monsiváis, "La intolerancia religiosa: 'Si no compartes mi fe, te parto la madre'", en Memoria del Seminario Internacional sobre Tolerancia.

${ }^{11}$ R. del Águila, "Los derechos humanos y algunos de sus problemas en el mundo de hoy", en op. cit., p. 31.

${ }^{12}$ Rachel Sieder y Jessica Witchell, "Impulsando las demandas indígenas a través de la ley: reflexiones sobre el proceso de paz en Guatemala", en P. Pitarch y J. López García, op. cit., p. 55.

${ }^{13}$ Rodolfo Stavenhagen, "Derechos humanos y derechos culturales de los pueblos indígenas", en Anuario Jurídico, vol. XII. México, UNAM, 1985, p. 375. 
La identidad de un pueblo no es algo dado, sino la imagen que se forma de sí mismo. Ésta cambia y se transforma según las circunstancias históricas $[. .$.$] no es un conjunto de características peculiares por des-$ cubrir, sino una representación ideal por proyectar. No es algo hecho, transmitido por la tradición, sino un proyecto renovado en cada momento, por el que se interpreta el pasado para darle un sentido en función de fines elegidos [...] y también incluye criterios para poner en cuestión ese legado y transformarlo siguiendo posibilidades abiertas de nuevas elecciones. ${ }^{14}$

El problema de la universalidad de los derechos humanos se puede enfrentar, así, desde dos posturas: la relativista y la universalista. Muchos relativistas niegan la universalidad de los derechos humanos, y muchos universalistas no han comprendido cabalmente la compleja problemática de las comunidades indígenas, que son alrededor de 300 millones de seres humanos en todo el mundo. Es cierto que los derechos humanos han de ser universales y que todo hombre tiene derecho a practicar la religión que elija, pero también es cierto que esta postura no ha sido favorable para las comunidades indígenas, pues relacionan la conversión a otros credos con el intento de integrarlos a la cultura nacional, que ha propiciado la desaparición de sus valores propios; de hecho, han tenido que renunciar a parte de su identidad cultural y adoptar valores de los grupos dominantes. Pero "lo que destruye la identidad de un pueblo -dice Luis Villoro- no es el cambio de sus formas de vida o de pensamiento, sino la negación de su capacidad de proyectar y realizar una imagen ideal de sí mismo en la que el pasado se integre con la realidad actual”. Lo que priva al otro de reinterpretar su identidad, como ocurrió en la conquista española y puede ocurrir hoy en la mayoría de las comunidades, es el afán de imposición y de dominio. Sólo el reconocimiento del carácter pluricultural y multiétnico del Estado, garantiza el respeto a la capacidad de decisión autónoma de los pueblos.

De este modo, en el terreno religioso, la conversión puede ser otra forma de imposición y de dominio, puede esconder un nuevo colonialismo, pues los protestantes y otros grupos religiosos creen ser portadores de valores universales, de mensajes que la propia divinidad les ha revelado; creen tener la única religión verdadera y estar cumpliendo con la misión sagrada de convertir a todos los demás.

Sin embargo, al lado del afán de conservar "la costumbre", ha surgido una élite intelectual indígena con actitud crítica y afán de progreso (indepen-

${ }^{14}$ Luis Villoro, Estado plural, pluralidad de culturas. México, Paidós/UnAm, Facultad de Filosofía y Letras, 1998, p. 149. 
dientemente de sus motivaciones personales), en la que está entonces la esperanza de que "las etnias tengan el control de sus propias organizaciones representativas y puedan sostener sus decisiones sin estar obligados a renunciar a su forma de vida". ${ }^{15}$ Estos grupos, conscientes de que la integración al Estado nacional y el individualismo que conlleva la conversión pueden atentar realmente contra su identidad y poner en peligro su sobrevivencia como culturas, han apoyado las ideas alternativas de Estado multicultural y poliétnico. ${ }^{16}$

Todo lo dicho impide que el relativismo cultural ponga en peligro el concepto de derechos humanos, en los que las mismas élites indígenas se han apoyado para sustentar sus demandas. La clave está en encontrar un sustrato básico de valores, por el que los derechos culturales y la identidad colectiva no se contrapongan a la universalidad de los derechos humanos ni a los derechos de los individuos a elegir religión y forma de vida. Tiene que hallarse un punto en que coincidan la libertad religiosa -y con ella el cumplimiento de los derechos humanos- y la salvaguarda de los derechos culturales. Debe haber ciertos valores comunes en la base de todas las legislaciones y asociaciones, que no sean, como dice Villoro, "consecuencia de la universalización de una sola cultura, sino del intercambio entre varias", ${ }^{17}$ y para que esto se logre, los miembros de las distintas culturas han de poder intercambiar sus puntos de vista en igualdad de condiciones de poder y en ausencia de toda coacción. ${ }^{18}$

Porque en verdad, como afirma Del Águila, todos somos sociedades multiculturales y multinacionales, incluso la propia concepción occidental puede y debe ser plural.

En estas condiciones - dice- se desarrolla una visión pluralista de la civilización de los derechos humanos que es nuestra obligación refinar y construir [...] y sobre esa base acaso sería posible desarrollar una civilización de los derechos humanos que no tuviera aparejada la coletilla de imperialista, sino las ideas de mutuo respeto y no discriminación. ${ }^{19}$

Y ese mínimo moral de los derechos humanos ha de incentivar la libertad, la no discriminación, la autonomía de las personas y de las comunidades; restringir el miedo, la violencia, la crueldad, las desigualdades estructurales y la miseria.

15 Ibid., p. 152.

${ }^{16}$ Idem.

${ }^{17}$ Ibid., p. 147.

18 Idem.

${ }^{19}$ R. del Águila, "Los derechos humanos y algunos de sus problemas en el mundo de hoy", en op. cit., p. 32. 
Las consideraciones que aquí hemos señalado muestran que en el mundo actual el camino hacia la libertad y la igualdad religiosas es ciertamente arduo, está plagado de múltiples escollos, está contaminado de muchas otras problemáticas, pero esa libertad y esa igualdad forman parte de la dignidad humana, cuya preservación es el mayor imperativo en cualquier sociedad actual. 